\title{
PRIZNAVANJE SORTI U REPUBLICI HRVATSKOJ
}

\author{
Marina ZORIĆ ${ }^{1}$, I. VARNICA ${ }^{1}$, G. JUKIĆ ${ }^{1}$, Ružica JURIĆ ${ }^{2}$ \\ ${ }^{1}$ Hrvatska agencija za poljoprivredu i hranu - Centar za sjemenarstvo i rasadničarstvo \\ Croatian Agency for Agriculture and Food - Center for Seed and Seedlings \\ ${ }^{2}$ Hrvatska agencija za poljoprivredu i hranu - Ured ravnatelja \\ Croatian Agency for Agriculture and Food - General manager office
}

\section{SAŽETAK}

Priznavanje sorti poljoprivrednog bilja u Republici Hrvatskoj provodi se u Hrvatskoj Agenciji za poljoprivredu i hranu - Centru za sjemenarstvo i rasadničarstvo u skladu sa Zakonom o sjemenu, sadnom materijalu i priznavanju sorti poljoprivrednog bilja (NN 140/05, 35/08, 25/09, 124/10, 55/11 i 14/14), Pravilnikom o upisu sorti u Sortnu listu (NN 45/08, 84/08, $77 / 13$, 136/15, 57/17, 70/18 i 75/19), Pravilnikom o priznavanju sorti poljoprivrednog bilja (NN 99/08, 100/09, 109/10, 77/13 i 57/18) i Pravilnikom o postupku utvrđivanja različitosti, ujednačenosti i postojanosti novih biljnih sorti u svrhu dodjeljivanja oplemenjivačkog prava i priznavanja sorti (NN 61/11).

Sortna lista Republike Hrvatske je službeni popis sorti vrsta bilja koje su priznate u Republici Hrvatskoj. Postupkom priznavanja sorte stječe se pravo upisa sorte u Sortnu listu Republike Hrvatske, Zajedničku sortnu listu Zajednice i OECD listu. Trenutno je na Sortnoj listi Republike Hrvatske upisano 843 sorti poljoprivrednog bilja i povrća.

Od osnivanja Centra za sjemenarstvo i rasadničarstvo (1998.) do danas je zaprimljen 4.181 zahtjev za priznavanje 103 biljne vrste. Od tog su broja priznate 2.409 sorti, 1.251 je povučeno iz ispitivanja, a 285 sorti nije priznato. Za 8 sorti je odbačen zahtjev za priznavanje i 228 sorti se nalazi u postupku ispitivanja.

Ključne riječi: sorta, priznavanje, Sortna lista Republike Hrvatske, Zajednička sortna lista Zajednice

\section{UVOD}

Upisom sorte u Sortnu listu Republike Hrvatske (u daljnjem tekstu: SLRH) poljoprivredni reprodukcijski materijal te sorte se može proizvoditi, prijaviti za stručni nadzor, staviti na tržište ili uvoziti i staviti na tržište. Upis u SLRH obvezan je za sljedeće biljne vrste: uljarice i predivo bilje, krmno bilje, žitarice, repe, povrće, krumpir i lozu. 
Pravo upisa sorte u SLRH se stječe postupkom priznavanja. Postupak priznavanja započinje podnošenjem zahtjeva za priznavanje sorte poljoprivrednog bilja Hrvatskoj Agenciji za poljoprivredu i hranu - Centru za sjemenarstvo i rasadničarstvo (u daljnjem tekstu: CSR).

Prije osnivanja Zavoda za sjemenarstvo i rasadničarstvo (današnji Centar za sjemenarstvo i rasadničarstvo) priznavanje sorti i upis na Sortnu listu bili su u nadležnosti Ministarstva poljoprivrede (Ministarstvo je do 2011. nosilo naziv Ministarstvo poljoprivrede, ribarstva i ruralnog razvoja). S osnivanjem Zavoda za sjemenarstvo i rasadničarstvo 1998. godine poslove iz područja priznavanja sorti poljoprivrednog bilja preuzima Zavod za sjemenarstvo i rasadničarstvo (CSR).

\section{MATERIJAL I METODE}

Ispitivanje sorte u svrhu priznavanja provodi se u pokusnom polju i laboratoriju. $U$ pokusnom polju se provodi ispitivanje gospodarske vrijednosti (VCU ispitivanje) i utvrđivanje različitosti, ujednačenosti i postojanosti novih biljnih sorti (DUS ispitivanje - Distinctness, Uniformity and Stability).

Ispitivanje gospodarske vrijednosti (VCU) sorata u pokusnom polju traje dvije uzastopne godine i provodi se u skladu s Pravilnikom o priznavanju sorti. U tijeku VCU ispitivanja jedne sorte ili hibrida u pokusnom polju i laboratoriju usporedba se obavlja s istim standardima. Standard je u proizvodnji jedna od najzastupljenijih sorti odnosno hibrid koji prema svojim biološkim i gospodarskim svojstvima ima veliku vrijednost za namjenu radi koje se ispituje nova sorta ili hibrid. Ispitivanje gospodarske vrijednosti ne provodi se za: sorte povrća, osim kod sorti industrijske cikorije; sorte trava koje nisu namijenjene za proizvodnju voluminozne krme; linije, hibride, klonove koji su namijenjeni isključivo za uporabu kao nasljedne komponente i kod drugih vrsta poljoprivrednog bilja kod kojih upis u Sortnu listu Republike Hrvatske nije obvezan.

Utvrđivanje različitosti, ujednačenosti i postojanosti sorti provodi se u skladu sa Pravilnikom o postupku utvrđivanja različitosti, ujednačenosti i postojanosti novih biljnih sorti u svrhu dodjeljivanja oplemenjivačkog prava i priznavanja sorti kojim se utvrđuje različitost, ujednačenost i postojanost (DUS) biljnih sorti u postupku priznavanja i International Union for the Protection ofnewVarietiesofPlants (UPOV) tehničkim vodičima preuzetim prema Uredbi o pristupanju Međunarodnoj konvenciji za zaštitu novih biljnih sorti te Community Plant Variety Office (CPVO) tehničkim vodičima.

Broj lokacija na kojima se provode poljski pokusi prema biljnim vrstama varira od 2 lokacije do 5 lokacija. Pokusna mjesta su: središnja Hrvatska, Baranja, zapadna Slavonija i istočna Slavonija (dvije lokacije). Pokusi za provođenje VCU ispitivanja se postavljaju po slučajnom bloknom rasporedu u četiri ponavljanja.

Centar za sjemenarstvo i rasadničarstvo obrađuje godišnje i konačne podatke iz pokusnog polja i laboratorija. Na temelju rezultata ispitivanja sorte u polju i laboratoriju te mišljenja stručnih radnih tijela (Radna grupa za strne žitarice, Radna grupa za kukuruz, Radna grupa za industrijsko bilje, Radna grupa za krmno bilje) Povjerenstvo 
za priznavanje sorti krmnog bilja, žitarica, repa, povrća, krumpira, uljarica i predivog bilja ocjenjuje je li udovoljeno uvjetima za priznavanje sorte.

Uvjeti za priznavanje sorte su sljedeći: (1) da je sorta različita, ujednačena i postojana odnosno da je izdano Pozitivno DUS izvješće za sortu,(2) da sorta ima odgovarajuću gospodarsku vrijednostu VCU ispitivanju u odnosu na sortu (ili sorte) standard i (3) da je ime sorte prihvatljivo u skladu sa Zakonom o sjemenu i sadnom materijalu i priznavanju sorti poljoprivrednog bilja i Pravilnikom o upisu sorti u Sortnu listu.

\section{REZULTATI I RASPRAVA}

U Centru za sjemenarstvo i rasadničarstvo u bazi podataka evidentirano je 7.187 sorti 179 biljnih vrsta. Od 7.187 sorti priznatoje 5.012 sorti, 1.519 je povučeno iz ispitivanja, 420 sorti nisu priznate i za 8 sorti je odbačen zahtjev za priznavanje. U postupku priznavanjaje 228 sorti.Od 5.012 priznatih sorti 4.169 sorti je obrisano sa Sortne liste.

Za sorte prijavljene u postupak priznavanja kao i za sorte koje su upisane i brisane u/iz Sortne liste Republike Hrvatske CSR vodi dosje o sorti. Temeljem zahtjeva za priznavanje sorte zaprimljenih u Ministarstvu poljoprivrede (prije osnivanja CSR) formirano je 515 dosjea sorti i temeljem zahtjeva za priznavanje zaprimljenih u CSR 4.181 dosje sorte. Za 2.491 sortu formirani su dosjei sorti na osnovi upisa sorte $u$ upisnike prije osnivanja Centra za sjemenarstvo i rasadničarstvo.Broj zaprimljenih zahtjeva za priznavanje sorte u CSR-uje prikazan u tablici 1 prema vremenskim intervalima zaprimanja.

Tablica 1. Broj zaprimljenih zahtjeva za priznavanje prema vremenskim intervalima

Table 1. Number of applications for registration submitted per time intervals

\begin{tabular}{ccc}
\hline $\mathrm{Br} / N r$ & $\begin{array}{c}\text { Vremenski interval } \\
\text { Time interval }\end{array}$ & $\begin{array}{c}\text { Broj zaprimljenih zahtjeva } \\
\text { Numberofapplications }\end{array}$ \\
\hline 1 & $1998-2000$ & 689 \\
2 & $2001-2005$ & 1.214 \\
3 & $2006-2010$ & 1.205 \\
4 & $2011-2015$ & 588 \\
5 & $2016-2020$ & 485 \\
\hline & Ukupno/Total & 4.181 \\
\hline
\end{tabular}

Broj zaprimljenih zahtjeva za priznavanje u CSR-u kroz godine se smanjuje (Grafikon 1), naročito od 2012. godine nakon potpisivanja Ugovora o pristupanju Republike Hrvatske Europskoj uniji 9. prosinca 2011. koji je stupio na snagu 1. srpnja 2013. Do izraženog smanjenja broja zaprimljenih zahtjeva za priznavanje došlo je u isto vrijeme kada je pristupanjem Republike Hrvatske Europskoj Uniji omogućeno 
stavljanje sorti odnosno hibrida koji su upisani na Zajedničku sortnu listu Zajednice, na tržište Republike Hrvatske, bez obveze upisa sorte na Sortnu listu Republike Hrvatske.

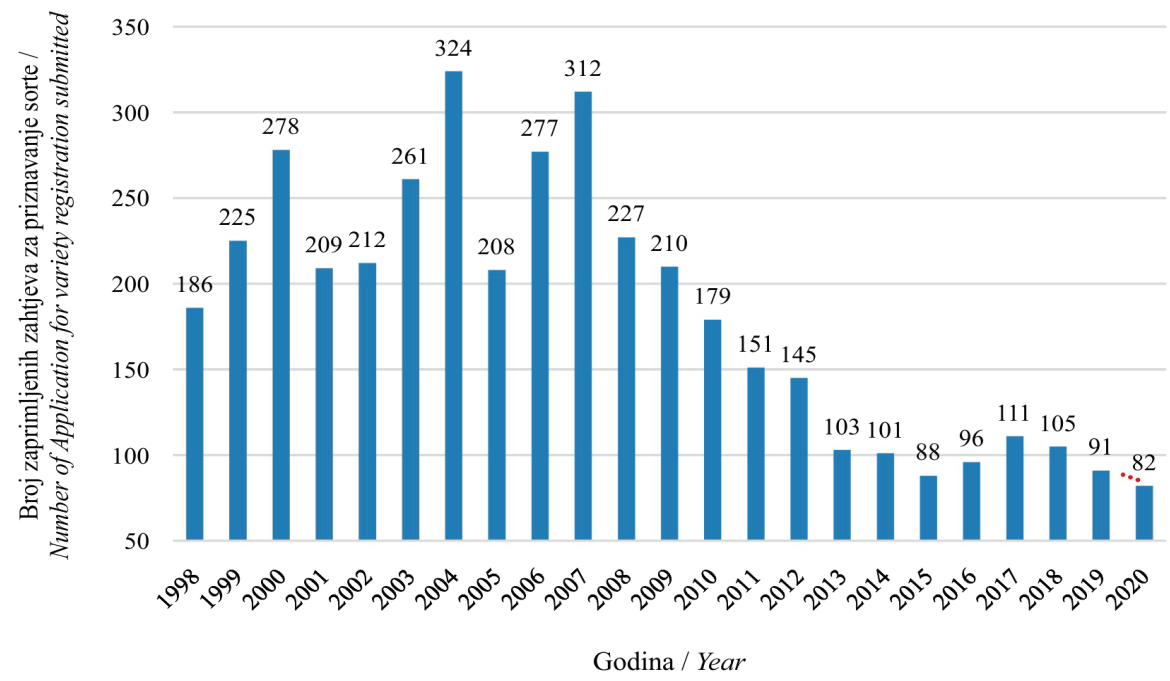

Grafikon 1. Broj zaprimljenih zahtjeva za priznavanje sorte od 1998. godine do 2020. godine Graph 1 Number of Applications for variety registration submitted from 1998 to 2020

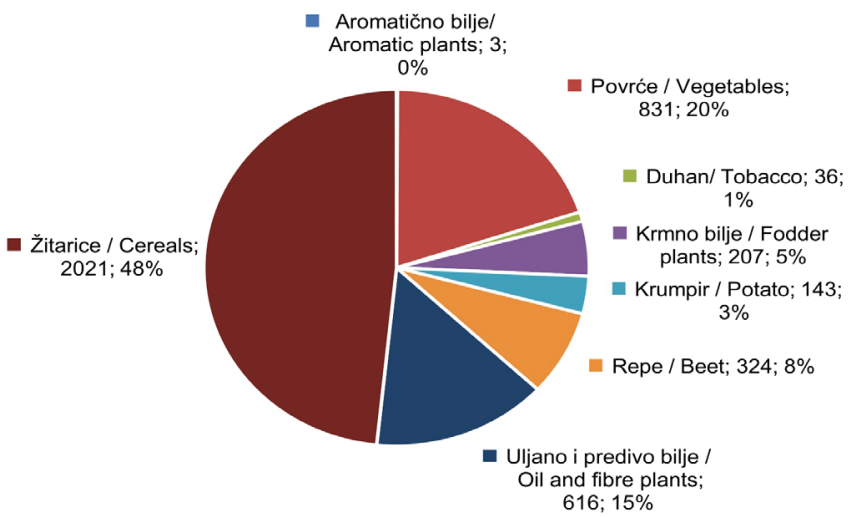

Grafikon 2. Broj zaprimljenih zahtjeva za priznavanje sorte u CSR-u i procentualni udio prema grupama bilja

Graph 2 Number of applications for variety registration submitted to CSS and percentage per groups of plants 
Najveći broj zaprimljenih zahtjeva za priznavanje sorte je za sorte iz grupe bilja žitarica 2021 zahtjev, povrtlarskog bilja 831 zahtjev i za uljano i predivo bilje 616 zahtjeva (Grafikon 2). Najmanje je zaprimljeno zahtjeva za priznavanje za aromatično bilje: 3 zahtjeva.

Od 4.181 sorte za koje su zaprimljeni zahtjevi za priznavanje u CSR-u, 2.409 sorti su priznate i temeljem rješenja o priznavanju upisane u Sortnu listu. Od toga broja 1.669 sorti je obrisano temeljem rješenja o brisanju sa Sortne liste, dokse 740 sorti nalazi upisano u Sortnoj listi Republike Hrvatske (Grafikon 3). Nakon prve odnosno druge godine ispitivanja u poljskim pokusima za 1.251 sortu je povučen zahtjev za priznavanje, što čini $30 \%$ podnesenih zahtjeva za priznavanje u CSR-u.

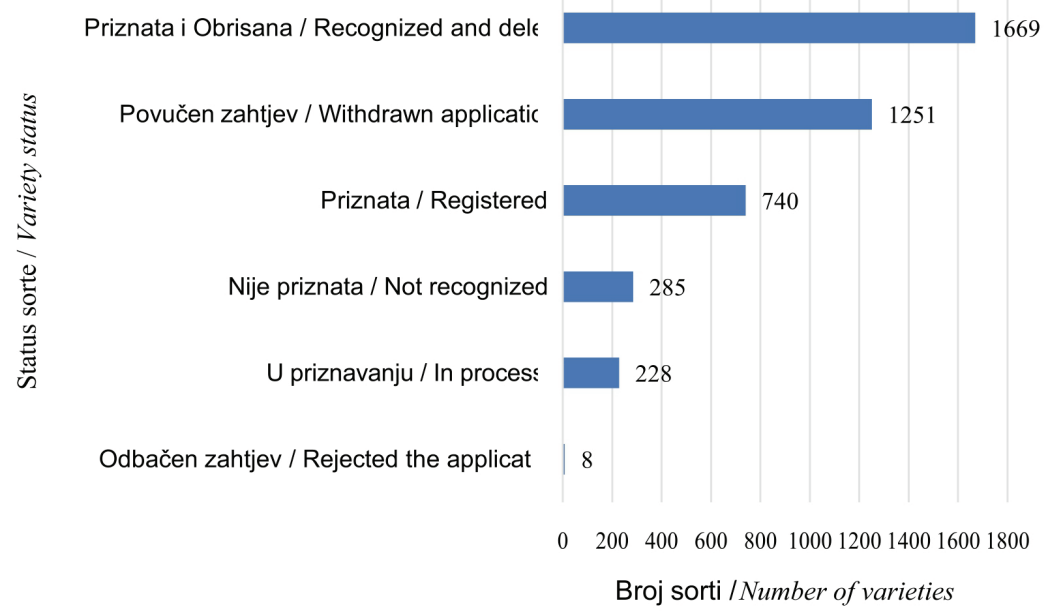

Grafikon 3. Pregled statusa sorti za koje su zaprimljeni zahtjevi za priznavanje u CSR-u

Graph 3 Overview of the varieties status for which applications for registration have been submitted to the CSS

Ispitivanje gospodarske vrijednosti sorte do 2008. godine trajalo je tri godine, a u 2009. godini sukladno izmjeni Pravilnika o priznavanju počinje se provoditi ispitivanje gospodarske vrijednosti sorte dvije godine.

Broj sorti u postupku priznavanja (VCU pokusi ratarskog bilja i sorte povrća) u periodu od 2000. godine do 2020. godine kreće se u rasponu od 130 sorti 2016. godine do 571 sorte 2000. godine. Ukupno u periodu od 2000. godine do 2020. godine u ispitivanju u svrhu priznavanja bilo je 7.288 sorti (Grafikon 4). 
Marina Zorić i sur.: Priznavanje sorti u Republici Hrvatskoj

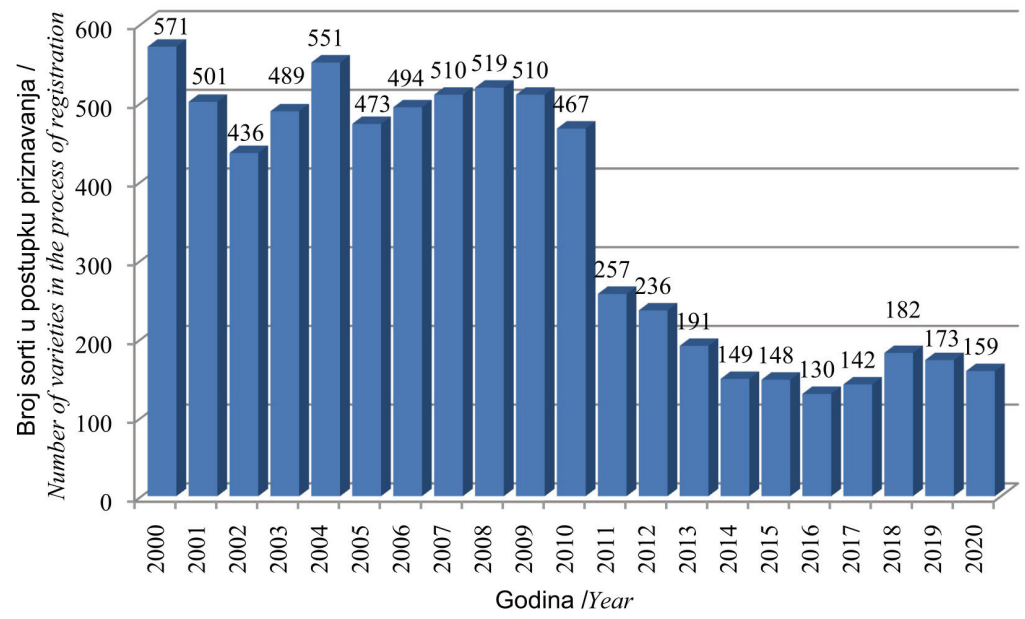

Grafikon 4. Broj sorti u postupku priznavanja u periodu od 2000. godine do 2020. godine Graph 4.Number of varieties in the process of registration in the period from 2000 to 2020 year

Nakon razmatranja rezultata VCU i DUS ispitivanja sorte Povjerenstvo za priznavanje sorti krmnog bilja, žitarica, repa, povrća, krumpira, uljarica i predivog bilja predlaže Ministarstvu poljoprivrede za sortu izdavanje rješenja o priznavanju odnosno nepriznavanju ovisno o rezultatu ispitivanja. Izdavanjem rješenja o priznavanju sorta stiče pravo na upis u Sortnu listu Republike Hrvatske i na Zajedničku sortnu listu Zajednice, kao i na OECD listu.

Sortna lista Republike Hrvatske je dinamičan popis sorti s obzirom da se u Sortnu listu Republike Hrvatske kontinuirano upisuju sorte i brišu sa Sortne liste. Trenutno se na Sortnoj listi Republike Hrvatske nalazi upisano 843 sorte.

Osim biljnih vrsta za koje je obvezujući upis u Sortnu listu Republike Hrvatske (i Zajedničku sortnu listu Zajednice) upisane su i sorte biljnih vrsta za koje nije obvezujući upis u SLRH: duhan, paštrnjak i hren. Najviše je upisano sorti u grupi žitarica 513 sorti i najmanje duhana 11 sorti (Grafikon 5). 


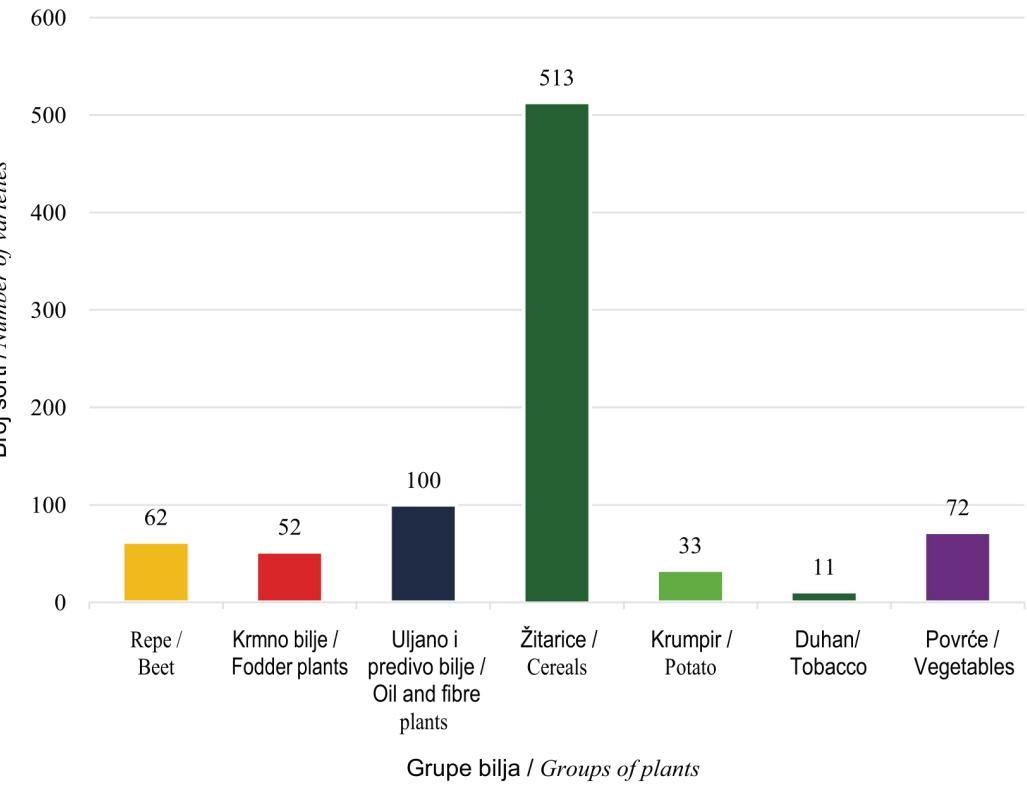

Grafikon 5. Broj sorti upisanih u Sortnu listu Republike Hrvatske prema grupama bilja Graph 5 Number of varieties entered in the Variety List of Varieties of the Republic of Croatia by groups of plants

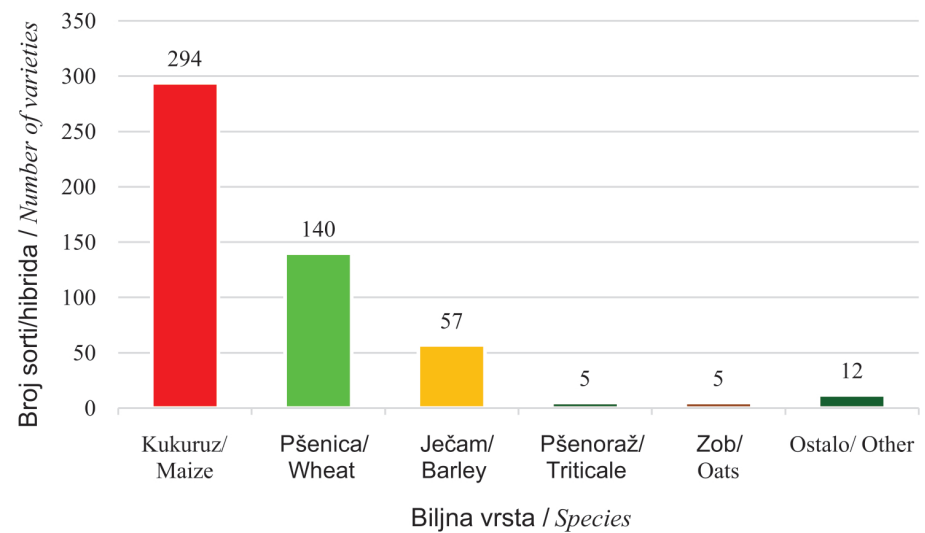

Grafikon 6. Broj sorti upisanih u Sortnu listu Republike Hrvatske u grupi žitarica Graph 6 Number of varieties entered in the Variety List of Varieties of the Republic of Croatia in the cereals group 
U grupi žitarica najveći broj upisanih sorti/hibrida u SLRH je za kukuruz 294 hibrida, zatim pšenice 129 sorti i ječma 57 (Grafikon 6). Od ostalih biljnih vrsta žitarica u SLRH su upisane sorte durum pšenice (3), raži (3), sirka (3), pravog pira (2) i hibrid između Sorghum Bicolor (L.) Moench i Sorghum Sudanense (Piper) Stapf.(1).

U grupi uljanog i predivog bilja upisane su 42 sorte/hibrida uljane repice, 29 hibridasuncokreta, 28 sorti soje i 1 sorta bijele gorušice.

U grupi krmnog bilja najviše je upisno u SLRH sorti lucerne (10), stočnog graška (8) i engleskog ljulja (7) što se može vidjeti u Tablici 2.

Tablica 2. Broj sorti upisanih u SLRH (Krmno bilje)

Table 2 Number of varieties entered in the Variety List of Varieties of the Republic of Croatia (Fodderplants)

\begin{tabular}{clc}
\hline $\mathrm{Br} /$ & \multicolumn{1}{c}{ Biljna vrsta / Species } & Broj sorti / Numberofvarieties \\
$\mathrm{Nr}$ & \multicolumn{1}{c}{10} \\
\hline 1 & Lucerna / Lucerne & 8 \\
2 & Stočni grašak / Fieldpea & 7 \\
3 & Engleski ljulj, Ljulj utrinac / Perennialryegrass & 5 \\
4 & Talijanski ljulj, Mnogocvjetni ljulj / Italianryegrass & 4 \\
5 & Crvena djetelina / Red clover & 4 \\
6 & Mačji repak / Timothy & 3 \\
7 & Klupčasta oštrica / Cocksfoot & 3 \\
8 & Vlasulja livadna / Meadowfescue & 3 \\
9 & Vlasulja trstikasta / Tallfescue & 2 \\
10 & Bijela djetelina / White clover & 2 \\
11 & Oldenburški ljulj/ Hybridryegrass & 1 \\
12 & Vlasulja nacrvena / Red fescue & 52 \\
\hline
\end{tabular}

U SLRH od povrtlarskog bilja najviše je upisano sorti paprike (11), kukuruza šećerca i rajčice po 8 sorti i češnjaka i kupusa po 6 sorti. Broj upisanih sorti povrtlarskih biljnih vrsta u SLRH je dat u Tablici 3.

U cilju očuvanja biljnih genetskih izvora »in situ« i održivog korištenja biljnih genetskih izvora kroz uzgoj mogu se priznati: domaće i udomaćene sorte te sorte koje nisu interesantne za uzgoj u komercijalne svrhe, ali su stvarane s ciljem uzgoja u posebnim uvjetima i upisuju se u SLRH kao čuvane sorte. U SLRH je upisano 28 čuvanih sorti (Tablica 4). 
Tablica 3. Broj sorti upisanih u SLRH (Povrtne vrste bilja)

Table 3 Number of varieties entered in the Variety List of Varieties of the Republic of Croatia (Vegetables)

\begin{tabular}{clc}
\hline $\mathrm{Br} / \mathrm{Nr}$ & \multicolumn{1}{c}{ Biljna vrsta / Species } & Broj sorti / Numberofvarieties \\
\hline 1 & Paprika / Sweetpepper & 11 \\
2 & Kukuruz šećerac / Sweetcorn & 8 \\
3 & Rajčica / Tomato & 8 \\
4 & Češnjak / Garlic & 6 \\
5 & Kupus bijeli/ White cabbage & 6 \\
6 & Kukuruz kokičar / Popcorn & 5 \\
7 & Luk / Onion & 5 \\
8 & Cvjetača / Cauliflower & 4 \\
9 & Kelj / Savoy cabbage & 3 \\
10 & Tikva/ Pumpkin-marrow & 3 \\
11 & Patliđan / Eggplant & 2 \\
12 & Salata / Lettuce & 2 \\
13 & Dinja / Melon & 1 \\
14 & Grah / Frenchbean & 1 \\
15 & Hren / Horseradish & 1 \\
16 & Krastavac / Cucumber & 1 \\
17 & Lubenica / Watermelon & 1 \\
18 & Matovilac / Cornsalad & 1 \\
19 & Paštrnjak / Parsnip & 1 \\
20 & Peršin / Parsley & 1 \\
21 & Postrna repa / Turnip & 1 \\
\hline & & Ukupno: / Total:
\end{tabular}

Tablica 4. Broj čuvanih sorti upisanih u SLRH

Table 4 Number of conservation varieties entered in the Variety List of Varieties of the Republic of Croatia

\begin{tabular}{llc}
\hline $\mathrm{Br} / \mathrm{Nr}$ & Biljna vrsta / Species & Broj sorti / Numberofvarieties \\
\hline 1 & Cešnjak / Garlic & 6 \\
2 & Luk / Onion & 5 \\
3 & Kupus bijeli/ White cabbage & 4 \\
4 & Paprika / Sweetpepper & 4 \\
5 & Rajčica / Tomato & 2 \\
6 & Grah / Frenchbean & 1 \\
7 & Hren / Horseradish & 1 \\
8 & Lubenica / Watermelon & 1 \\
9 & Paštrnjak / Parsnip & 1 \\
10 & Peršin / Parsley & 1 \\
11 & Postrna repa / Turnip & 1 \\
12 & Salata / Lettuce & 1 \\
\hline & Ukupno: / Total: & 28 \\
\hline
\end{tabular}




\section{ZAKLJUČAK}

Broj podnesenih zahtjeva za priznavanje sorte se od 1998. godine do 2020. godine smanjivao. U petogodišnjim periodima od 2001. godine do 2005. godine i od 2006. godine do 2010. godine zaprimljeno je dva puta više zahtjeva nego u periodima od 2011. godine do 2015. godine i od 2016. godine do 2020. godine. Smanjenje podnesenih zahtjeva može se povezati s ulaskom Republike Hrvatske u Europsku Uniju odnosno s mogućnosti da se sorte iz Europske Unije stavljaju na tržište bez obveze upisa u Sortnu listu Republike Hrvatske ukoliko su već upisane na Zajedničkoj sortnoj listi Zajednice.

U Sortnu listu Republike Hrvatske upisano je 843 sorti. Najviše sorti je upisano u grupi žitarica 513 sorti (61\%), uljanog i predivog bilja 100 sorti (12\%) i povrća 72 sorte $(9 \%)$.

Najveći broj sorti upisan u Sortnu listu Republike Hrvatske prema biljnim vrstama je za kukuruz (294 sorte), pšenicu (140 sorti) i za ječam (57 sorti).

\section{VARIETIES REGISTRATION IN THE REPUBLIC OF CROATIA}

\section{SUMMARY}

Registration of varieties of agricultural plants is conducted in the Croatian Agency for Agriculture and Food - Center for Seed and Seedlings in accordance with The Act on Seeds, Planting Material and Registration of Varieties of Agricultural Plants (OG 140/05, 35/08, 25/09, 124/10, 55/11 and 14/14), The Regulations on the Inclusion of Varieties in the National List of Varieties of Agricultural Plants (OG 45/08, 84/08, 77/13, 136/15, 57/17, $70 / 18$ and 75/19), The Regulations on the Registration of Varieties of Agricultural Plants (OG 99/08, 100/09, 109/10, 77/13 and 57/18) and The Regulations on the procedure and the conduct of tests for distinctness, uniformity and stability (DUS) of new varieties of plants for the purpose of granting the Breeders' Right (OG 61 / 11).

The variety list of the Republic of Croatia is an official list of varieties of certain plant species registered in the Republic of Croatia. To become eligible for inclusion in the List of Varieties of the Republic of Croatia, The Common Catalogue of Varietie sand OECD list, a variety must be registered.

Currently, 843 varieties of agricultural plants and vegetables are entered on The variety list of the Republic of Croatia. Since the establishment of the Center for Seedand Seedlings (1998), 4.181 applications for registration have been submitted for 103 plant species. Of that number, 2.409 varieties were 
registered, 1.251 were with drawn from testing and 285 varieties were not recognized. For 8 varieties, the Application for registration was rejected and 228 varieties are in the process of testing.

Keywords: variety, registration, Thevariety list of the Republic of Croatia, The Common Catalogue of Varieties

\section{LITERATURA - REFERENCES}

1. Zakon o sjemenu, sadnom materijalu i priznavanju sorti poljoprivrednog bilja (NN 140/05, 35/08, 25/09, 124/10, 55/11 i 14/14).

2. Pravilnik o upisu sorti u Sortnu listu (NN 45/08, 84/08, 77/13, 136/15, 57/17, 70/18 i 75/19).

3. Pravilnik o priznavanju sorti poljoprivrednog bilja (NN 99/08, 100/09, 109/10, 77/13 i 57/18).

4. Pravilnik o postupku utvrđivanja različitosti, ujednačenosti i postojanosti novih biljnih sorti u svrhu dodjeljivanja oplemenjivačkog prava i priznavanja sorti (NN 61/11).

\footnotetext{
Adresa autora - Author's address:

Mr.sc. Marina Zorić

Ivan Varnica, dipl.ing.

Dr.sc. Goran Jukić

Hrvatska agencija za poljoprivredu i hranu

Centar za sjemenarstvo i rasadničarstvo

Usorska 19, Brijest - Osijek

Tel. 38531275716

Fax. 38531275716

E-mail: marina.zoric@hapih.hr

Mr.sc. Ružica Jurić

Hrvatska agencija za poljoprivredu i hranu

Vinkovačka cesta $63 \mathrm{c}, 31000$ Osijek
}

Primljeno - Received:

03.11.2020. 
